\title{
DETECTION OF SOME DRUGS OF ABUSE FROM FINGERPRINTS USING LIQUID CHROMATOGRAPHY- MASS SPECTROMETRY
}

\author{
Ragaa Talaat Said Darwish', Maha Adel Mohamed El Demellawy², Haidy Moustafa \\ Abd El Salam Megahed ${ }^{1}$, Doreen Nazeih Younan ${ }^{3}$, Wael Saad Abd El Razek Kholeif ${ }^{1}$. \\ 1 Department of Forensic Medicine and Clinical Toxicology, Faculty of Medicine, \\ Alexandria University, Egypt \\ 2 Department of Medical Biotechnology, Genetic Engineering \& Biotechnology \\ Research Institute, City of Scientific Research \& Technology Applications, Egypt \\ Department of Clinical and Chemical Pathology, Faculty of Medicine, Alexandria \\ University, Egypt
}

\begin{abstract}
Rationale and background: Drug abuse is considered a major contributor to both medical morbidity and mortality all over the world. It also represents an important health problem that has a great impact on the person's life both socially and economically. A few methodologies have been created for the identification of drugs of abuse "for example liquid chromatography-mass spectrometry (LC-MS). The aim of this work was to assess the possibility of detection of some drugs of abuse from fingerprints using LC-MS. Participants and methods: This study was conducted on 60 male participants. The diagnosis of drug abusers was based on the current Diagnostic and Statistical Manual of Mental disorders (DSM-V) and urine screening tests. These participants were classified into 2 groups; a control group consisted of 30 normal individuals (non-drug abusers) and a drug abuser group consisted of 30 individuals that abused tramadol or clonazepam or phenobarbital (10 individuals for each drug). Fingerprint imprints from all participants were taken on a filter paper previously soaked with methanol then LC-MS analysis was performed. The concentration of drugs in each sample was calculated using the regression equations between concentration in $\mathrm{ng} / \mathrm{ml}$ and peak area of each reference standard. Results: All samples from drug abusers showed positive results with LC-MS, while all samples from the control individuals showed negative results. As regard the concentration of the drugs calculated in the drug abuser group, there was a significant increase among urban areas, secondary school, workers and those having positive family history. Conclusions and recommendations: The results of this study confirmed the possibility of detection of some drugs of abuse from fingerprints using LC-MS. So it is recommended to verify the applicability of this method in criminal cases involving drug handlers or on documents touched by abusers when only trace evidences are to be detected.
\end{abstract}

Keywords: Fingerprints, Drugs of abuse, Liquid chromatography-mass spectrometry, Tramadol, Clonazepam and Phenobarbital.

\section{INTRODUCTION}

The use and misuse of mindaltering substances have existed since antiquity. Drug abuse is now one of the major health problems and is implicated in many deaths, both directly from overdose and indirectly as a result of injuries taking place while the individual is intoxicated. Furthermore, the number of available 
pharmaceuticals has increased greatly during the last few decades, as well as their social use and dependence. In addition, a large number of illicit drugs containing psychoactive substances are consumed each year (Jones et al., 2015).

Most governments have planned enactment to criminalize certain sorts of medication abuse. These medications are frequently called "controlled substances" or "unlawful medications" because of their unlicensed production, distribution, and possession. Notwithstanding for straightforward ownership, legitimate discipline can be very serious (counting capital punishment in few nations). Laws shift crosswise over nations, and even inside them, and have changed broadly all through history. Attempts by government-supported drug control approach to prohibit drug supply and take out drug abuse have been to a great extent unsuccessful (Copeman, 2003 and Wood et al., 2003).

The testing of drug abuse is authentic in order to affirm the misuse of drugs and the testing technique is generally performed by examination of urine, blood and hair. However, numerous issues of test getting troubles and risk of adulteration show up. The utilization of alternative biological samples for example, saliva, skin, sweat, fingerprint deposits, exhaled breath and fingernail in drug testing exhibits some advantages and initiates more consideration (Barnes et al., 2008, Chen et al., 2012 and Clemons et al., 2013).

Fingerprints are the contact impression of the elevated portion of the friction ridge skin (Saferstein, 2006).

The nature of friction ridge skin on the palms of the hands and soles of the feet are novel to every person. This special example has been utilized as a part of forensic investigations to set up the identity of a person from centuries (Czekanski et al., 2006).

Each skin ridge is populated by a solitary line of pores, through which sweat is discharged and saved on the surface of the skin. The likelihood that a fingerprint can give more data about a person, than just identity, is energizing. For example, information about whether a person has handled drugs of abuse (Leggett et al., 2007 and Hazarika et al., 2010) or has been in contact with explosive materials, (Ifa et al., 2008 and $\mathrm{Ng}$ et al., 2009) has recently been accounted for utilizing techniques to develop latent fingerprints.

In criminal investigations, fingerprints might fill in as an essential biological sample for drug testing notwithstanding their customary use in identifying individuals (Kuwayama et al., 2014).

In forensic and clinical toxicology, analytical methods must give high reliability and accuracy. The combinations of MS with suitable chromatographic procedures are the techniques of choice, since they are extremely sensitive, precise and specific. Today, LC-MS is the brilliant standard for detection and quantification of non-volatile drugs and toxins (Jones et al., 2015).

Liquid chromatography is an analytical technique in which diverse molecules partition themselves to different extents between a liquid mobile phase and solid stationary phase. LC is used to isolate an extensive variety of polar and non-polar compounds, from low molecular-weight organic and inorganic compounds to high-molecularweight proteins and nucleic acids. The 
use of mass spectrometric detection after a chromatographic separation is an especially intense blend in which many mixes co-elute and particle separation is required for unambiguous discovery and quantification (Ifa et al., 2008).

LC-MS is applied in an extensive variety of areas including biotechnology, environment monitoring, nourishment handling, drugs, agrochemical, and cosmetic industries (Chaimbault, 2014).

\section{AIM OF THE WORK}

The aim of the present study was to assess the possibility of detection of some drugs of abuse from fingerprint imprints using LC-MS.

\section{PARTICIPANTS \& METHODS}

\section{The study population:}

This case-control study was conducted on 60 randomly selected male individuals admitted to private clinics and centers for treatment of drug dependence in Alexandria, Egypt, in the period between the $1^{\text {st }}$ of May and the $30^{\text {th }}$ of November 2016.

Participants were interviewed and a written informed consent was obtained from every participant for history taking and for the permission to take a urine sample and fingerprint imprint for subsequent examination of the presence or absence of the drugs of abuse.

In this study, the participants were classified into 2 groups:

Group I (control group): composed of 30 normal males (nondrug abusers). Their age ranged from 18-35 years.

Group II (drug abuser group): composed of 30 male drug abusers. They abused either tramadol or clonazepam or phenobarbital (10 individuals for each drug) with comparable age to the control group.

Diagnosis of drug dependence was based on the current Diagnostic and Statistical Manual of Mental Disorders (DSM-V) (American Psychiatric Association, 2013) and urine screening tests.

\section{Urine samples:}

Screening test for the drugs of abuse was made using urine samples from all participants. The results of the urine screening tests appeared in the form of lines on the test cards (manufacture by abon biopharm company, China) to indicate the presence or absence of various substances (Raes and Verstraete, 2005).

\section{Fingerprint samples:}

Fingerprint imprints from all participants were taken on a filter paper previously soaked with methanol.

LC-MS analysis of the fingerprints

LC-MS analysis of the fingerprint imprints on a filter paper was performed in the Center of Pharmaceutical and Fermentation Industry Development, City for Scientific Research and Technology Application, Borg El-Arab, Alexandria, Egypt.

The study was done using LC-MS (SCIEX Triple Quad or QTRAP 5500 System) using Eclipse XDB-C18 column (particle size: $3.5 \mu \mathrm{m}$, I.D: 4.6 $\mathrm{mm}$ and length: $100 \mathrm{~mm}$ ).

Preparation of the standards:

- Chromatographic separation mobile phase was a gradient of ammonium formate or acetate, water, methanol and/or acetonitrile.

- Stock solutions of drugs of abuse (tramadol, clonazepam and phenobarbital) were prepared in 
methanol at a concentration of 500 $\mathrm{ng} / \mathrm{ml}$ (by taking $0.5 \mathrm{ml}$ of $100 \mu \mathrm{g} / \mathrm{ml}$ of each drug and completing it to $100 \mathrm{ml}$ methanol). These stocks of $500 \mathrm{ng} / \mathrm{ml}$ were used for the preparation of calibration standards.

For the calibration standards, the stock solution was further diluted to obtain working solutions in a range from 0.1 to $150 \mathrm{ng} / \mathrm{ml}$ for tramadol and from 0.1 to $175 \mathrm{ng} / \mathrm{ml}$ for both clonazepam and phenobarbital.

Preparation and analysis of the sample:

- Filter papers were soaked in methanol and vortexed for $1 \mathrm{~min}$ to ensure that all the drugs in the filter paper were dissolved in the solvent.

- The analysis was performed using ekspert ${ }^{\mathrm{TM}}$ ultra LC system (Dublin, CA, USA). The analytical column was Agilent ZORBAX Eclipse XDB-C 18 column $(5 \mu \mathrm{m}, 100 \times 4.6 \mathrm{~mm}$, pore size $80 \AA$ ) maintained at $30^{\circ} \mathrm{C}$. The mobile phase was composed of $0.1 \%$ formic acid in water (glass distilled water was further purified using Milli-Q water purification system Millipore, Bedford, MA, USA) and LC grade methanol. The elution was carried out in a gradient mode which runs in $20 \mathrm{~min}$. The flow rate was $800 \mu \mathrm{L} / \mathrm{min}$ and the injection volume was $20 \mu \mathrm{L}$.

- The Ultra-Performance LC system was coupled on-line to $\mathrm{AB}$ SCIEX Triple Quad 5500 MS equipped with Turbo $\mathrm{V}^{\mathrm{TM}}$ ion source operated in a positive ion mode for both tramadol and clonazepam and in a negative ion mode for phenobarbital.

- The turbo gas temperature was set at $600^{\circ} \mathrm{C}$ and Turbolon needle voltage was adjusted to $5500 \mathrm{~V}$.

- Data acquisition and processing was performed using Analyst software 1.6 (AB Sciex, Darmstadt, Germany).

- Concentration of drugs in each sample was calculated using the regression equations between concentration in $\mathrm{ng} / \mathrm{ml}$ and peak area of each reference standard (Table1) and (Figs. 1-3)

Table (1): Molecular ion/product ion and retention time (min)

\begin{tabular}{|c|c|c|c|}
\hline No & Compound & Molecular ion/product ion & Retention time (min) \\
\hline 1 & Tramadol & $264 / 58$ & 7.10 \\
\hline 2 & Clonazepam & $315.5 / 270$ & 10.27 \\
\hline 3 & Phenobarbital & $231 / 41.9$ & 8.68 \\
\hline
\end{tabular}


U XIC of +MRM (9 pairs): Exp 1, 284.07 158.000 Da ID: Tr fiom Sample 19 (Std_175.0ng_MeOH_gradient_waterwFA_MeOH_0.8_..

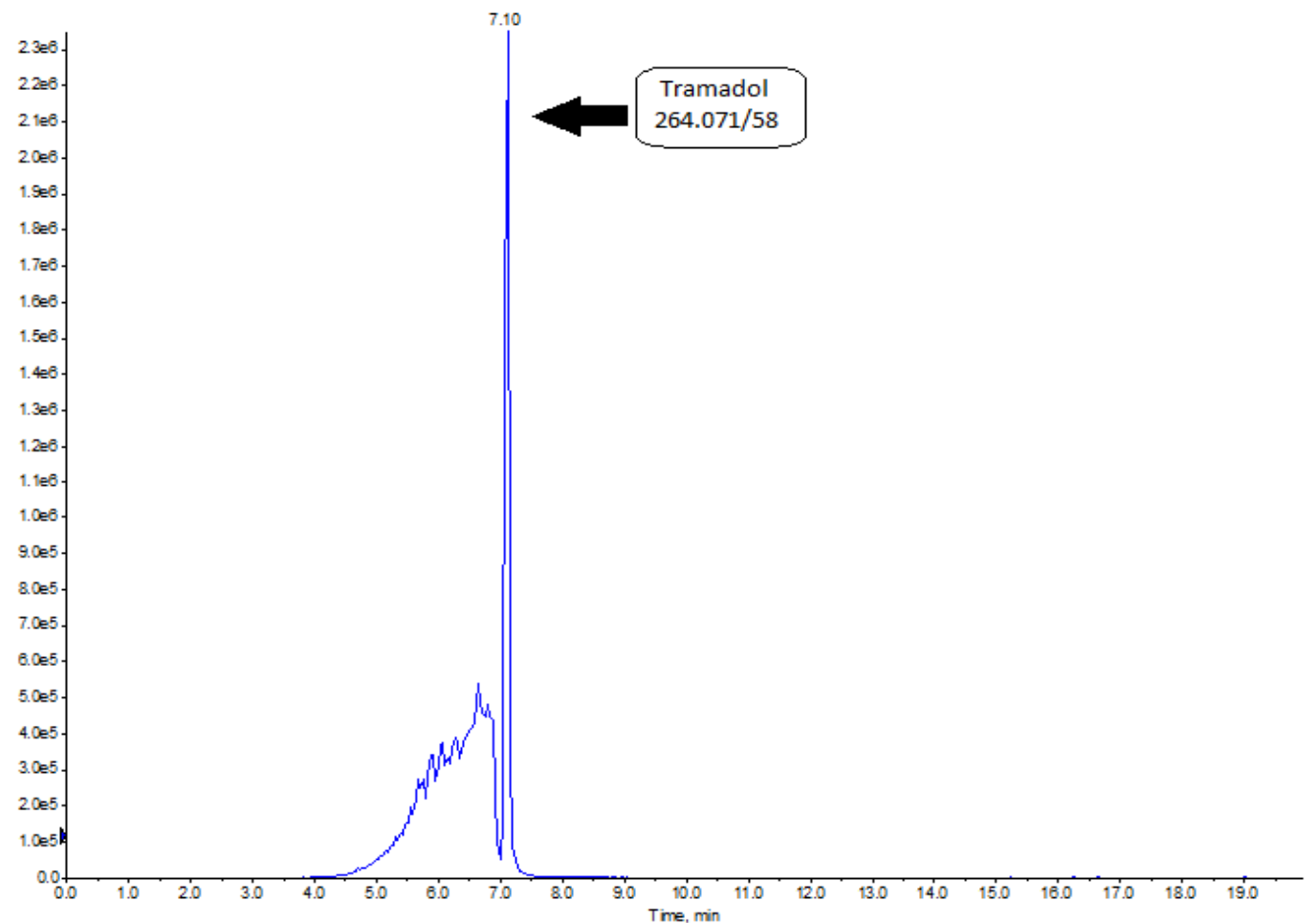

Figure (1): Chromatogram of tramadol

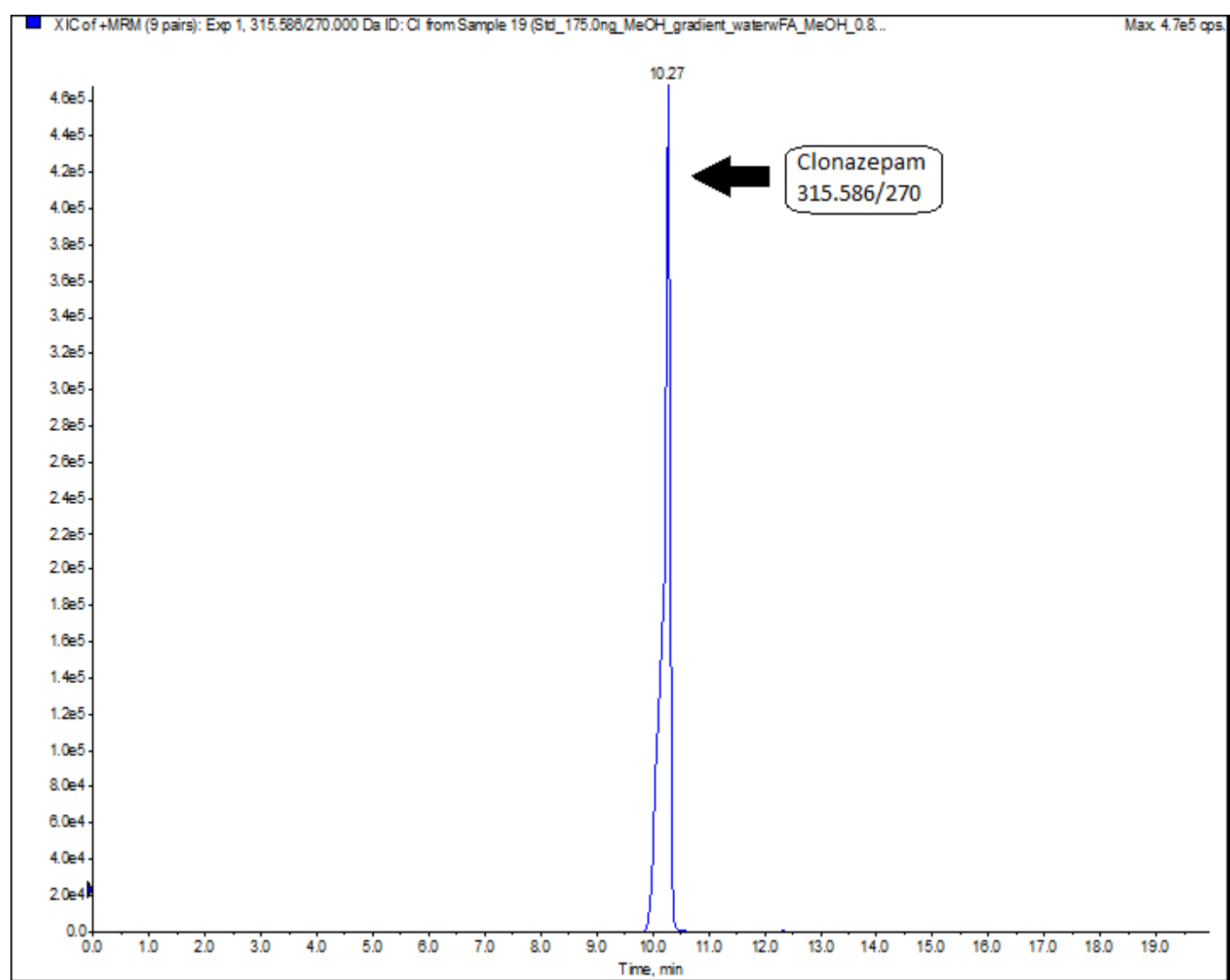

Figure (2): Chromatogram of clonazepam 


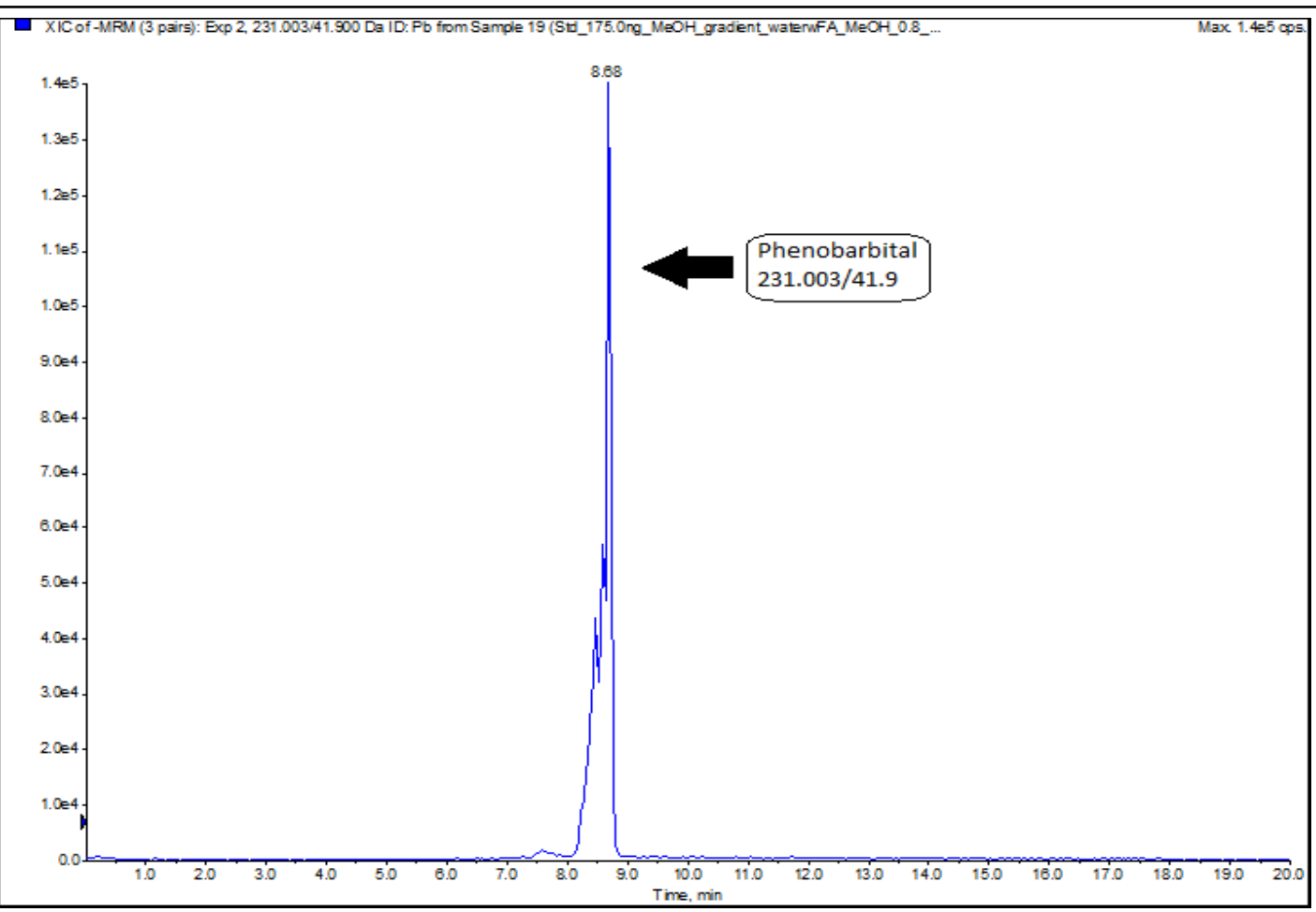

Figure (3): Chromatogram of phenobarbital

\section{Data processing and analysis}

After data was collected, it was revised, coded and fed to statistical software IBM SPSS version 20. All data was subjected to descriptive and analytical statistics. Statistical analysis was done using two tailed tests and alpha error of $\mathbf{0 . 0 5}$. $\mathrm{P}$ value less than or equal to $\mathbf{0 . 0 5}$ was considered to be statistically significant.

\section{RESULTS}

The study was conducted on 60 male participants (30 drug abusers and 30 control individuals of the same age and sex). The diagnosis of drug dependence was based on the current Diagnostic and Statistical Manual of Mental Disorders (DSM-V) and screening tests on urine for tramadol, clonazepam and phenobarbital.

Demographic data of the drug abuser individuals:

- Age: Age of the studied drug abuser group ranged from 18 to 35 years with a mean of $24.6 \pm 4.4$ years.
There was no statistically significant difference between the mean age of drug abusers and the control group.

- Residence: The majority (60\%) of drug abusers in the present study was from urban areas (Table 2).

- Education: The present study showed that $20 \%$ of the studied individuals had terminated their education at secondary school level, $40 \%$ were university graduates, while $40 \%$ were illiterate (Table 2).

- Occupation: In the present study, the highest percentage of drug abusers (40\%) was among manual and skilled workers, while unemployed individuals, employees and students each represented 20\% (Table 2).

- Family history: The majority of drug abusers in the present study (60\%) had positive family history of substance abuse. The family members involved were parents, uncles, cousins or siblings (Table 2).

Liquid chromatography-mass spectro-metry results: 
All samples from drug abusers showed positive results with LC-MS, while all samples from the control individuals showed negative results which means that the test has $100 \%$ specificity and sensitivity as shown in Table (3).

1. Concentration of drugs of abuse in the examined fingerprint samples:

Table (4) shows a significant difference between mean concentration \pm SD of tramadol $(9.29 \pm 10.16)$ and mean concentration $\pm \mathrm{SD}$ of clonazepam $(3.87 \pm 0.01), \quad \mathrm{p}=0.018$ and also illustrates a significant difference between mean concentration of tramadol and mean concentration \pm SD of phenobarbital $\quad(3.43 \pm 0.60) \quad \mathrm{p}=0.020$. However there was no significant difference between mean concentration of clonazepam and Phenobarbital where $\mathrm{p}=0.405$.

\section{Relation between} concentration of the drugs and duration of abuse:

Among abusers the mean concentration of the drugs in the examined samples was highest when the duration of abuse was more than two years $(27.2 \pm 6.4,3.88 \pm 0.02$ and $4.2 \pm 0.2$ for tramadol, clonazepam and phenobarbital respectively), while it was the least when the duration of the abuse was less than one year $(1.5 \pm 0.2$, $3.86 \pm 0.01$ and $2.8 \pm 0.1$ for tramadol, clonazepam and phenobarbital respectively) which was significantly different in case of clonazepam $p=0.034$ and not significant in case of tramadol and phenobarbital $\mathrm{p}=0.064$ and 0.05 . This means that the longer the duration of drug intake, the higher concentration of drugs in the fingerprints. Table (5)
3. Relation between age and concentration of the drugs calculated in the drug abuser group:

The mean concentrations of tramadol, clonazepam and phenobarbital in the abuser group were higher among age group between18$<25$ years $(17.73 \pm 11.51,3.88 \pm 0.03$ and $4.04 \pm 0.30 \mathrm{ng} / \mathrm{ml}$ respectively) than the other 2 age groups; $25-<30$ and 30-35 years. The age group between 30-35 years showed the lowest mean concentration of drugs of abuse $(1.44 \pm 0.17,3.87 \pm 0.02$ and $2.87 \pm 0.31$ respectively). There was a significant difference between all age groups abusing tramadol, clonazepam and Phenobarbital where $\mathrm{p}$ value for tramadol $=0.018$ and for both Phenobarbital and clonazepam $=0.030$. Table (6)

4. Relation between residence and concentration of the drugs calculated in the drug abuser group:

Comparison between urban and rural areas regarding the mean concentration of drugs of abuse among drug abusers revealed a significant difference as in urban areas, the mean concentrations of tramadol, clonazepam and phenobarbital (17.73 \pm 11.51 , $3.88 \pm 0.04$ and $3.98 \pm 0.41$ respectively) were higher than in the rural areas $(3.66 \pm 3.37,3.87 \pm 0.02$ and $3.06 \pm 0.38$ respectively) where $p$ value for tramadol $=0.011$ and for both phenobarbital and clonazepam $=0.019$. Table (7)

5. Relation between education and concentration of the drugs calculated in drug abusers:

Table (8) depicts a significant difference between the mean concentration of drugs and education in the abuser group. The mean concentration of tramadol, clonazepam 
and phenobarbital among the highly educated abusers (the university graduates) was significantly higher than the other 2 groups; the non-educated (the illiterate group) (17.73 \pm 11.51 , $3.88 \pm 0.04,4.04 \pm 0.30$ and $4.81 \pm 3.70$, $3.87 \pm 0.03,3.17 \pm 0.23$ respectively)and the secondary school abusers which showed the least mean concentration for these drugs $(1.36 \pm 0.14,3.86 \pm 0.02$ and $2.70 \pm 0.12$ respectively) where $p$ value for tramadol and Phenobarbital $=$ 0.020 and for clonazepam $=0.051$.

6. Relation between occupation and concentration of drugs in the drug abuser group:

Table (9) demonstrates that the mean concentration of tramadol, clonazepam and phenobarbital was significantly higher among workers $(17.73 \pm 11.51,3.89 \pm 0.02$ and $4.04 \pm 0.30$ respectively) followed by students $(8.01 \pm 0.18, \quad 3.88 \pm 0.01$ and $\quad 3.31 \pm 0.14$ respectively) and followed by employee $(1.61 \pm 0.01,3.87 \pm 0.02$ and $2.91 \pm 0.06$ respectively). The unemployed group showed the least mean concentration of drugs of abuse $(1.36 \pm 0.14,3.86 \pm 0.02$ and $2.82 \pm 0.41$ respectively) where $p$ value for tramadol $=0.040$ and for Phenobarbital and clonazepam $=0.049$.

7. Relation between family history of abuse and concentration of the drugs calculated in the drug abuser group:

Comparative statistics of the means and standard deviations for the concentration of tramadol, clonazepam and phenobarbital among abusers with positive family history $(\mathrm{FH})$ and those with negative $\mathrm{FH}$ are presented in table (10). In case of abusers with positive FH, it was found that the mean concentrations of tramadol, clonazepam and phenobarbital $(14.49 \pm 10.23,3.88 \pm 0.04$ and $3.77 \pm 0.49$ respectively) were significantly higher than those of abusers with negative FH $(1.49 \pm 0.17,3.87 \pm 0.02$ and $2.92 \pm 0.34$ respectively) where $p$ value for tramadol $=0.011$, for clonazepam $=0.019$ and for Phenobarbital $=0.033$.

Table (2): Descriptive data of the drug abusers $(n=30)$

\begin{tabular}{|l|l|c|c|}
\hline \multicolumn{2}{|c|}{ Parameters } & n & \% \\
\hline \multirow{5}{*}{ Age (years) } & $18-20$ & 3 & 10 \\
\cline { 2 - 4 } & $>20-25$ & 20 & 66.7 \\
\cline { 2 - 4 } & $>25-30$ & 3 & 10 \\
\cline { 2 - 4 } & $>30-35$ & 4 & 13.3 \\
\hline \multirow{4}{*}{ Residence } & Urban & 18 & 60 \\
\cline { 2 - 4 } & Rural & 12 & 40 \\
\hline \multirow{5}{*}{ Education } & High education (university) & 12 & 40 \\
\cline { 2 - 4 } & Secondary school & 6 & 20 \\
\cline { 2 - 4 } & Illiterate & 12 & 40 \\
\hline \multirow{5}{*}{$\begin{array}{c}\text { Oampation } \\
\text { of substance abuse }\end{array}$} & Worker (manual \& skilled) & 12 & 40 \\
\cline { 2 - 4 } & Employee & 6 & 20 \\
\cline { 2 - 4 } & Student & 6 & 20 \\
\cline { 2 - 4 } & Unemployed & 18 & 60 \\
\cline { 2 - 4 } & Present & 12 & 40 \\
\hline
\end{tabular}


Table (3): Comparison between the studied groups according to sensitivity and specificity calculated in each group

\begin{tabular}{|l|c|c|c|c|c|c|c|}
\hline LC-MS Results & \multicolumn{2}{|c|}{ Controls } & \multicolumn{2}{|c|}{ Cases (abuser) } & \multirow{2}{*}{ P } & \multirow{2}{*}{ Sensitivity } & Specificity \\
\cline { 1 - 5 } & $\mathbf{n}$ & $\mathbf{\%}$ & $\mathbf{n}$ & $\boldsymbol{\%}$ & & & \\
\cline { 1 - 6 }$+\mathrm{ve}$ & 30 & 100 & 0 & 0.0 & $<0.001^{*}$ & 100.0 & 100.0 \\
\hline
\end{tabular}

$*$ : Statistically significant at $\mathbf{p} \leq \mathbf{0 . 0 5}$

Table (4): Concentration of the drugs in the examined fingerprint imprints in the drug abuser group $(n=30)$

\begin{tabular}{|l|c|c|c|c|}
\hline & $\begin{array}{c}\text { Tramadol } \\
(\mathbf{n = 1 0})\end{array}$ & $\begin{array}{c}\text { Clonazepam } \\
(\mathbf{n}=\mathbf{1 0})\end{array}$ & $\begin{array}{c}\text { Phenobarbital } \\
(\mathbf{n}=\mathbf{1 0})\end{array}$ & $\mathbf{H}$ \\
\cline { 1 - 4 } Concentration calculated $(\mathbf{n g} / \mathbf{m l})$ & & & & \\
\cline { 1 - 4 } Min.-Max. & $1.26-31.68$ & $3.86-3.88$ & $2.62-4.39$ & \multirow{2}{*}{1.806} \\
\cline { 1 - 3 } \pm Mean. & $9.29 \pm 10.16$ & $3.87^{\mathrm{a}} \pm 0.01$ & $3.43^{\mathrm{b}} \pm^{\mathrm{c}} 0.60$ & \\
\cline { 1 - 3 } Median & 8.01 & 3.87 & 3.31 & \\
\hline
\end{tabular}

H,p: $H$ and p values for Kruskal Wallis test,

Sig. bet. grps was done using Mann Whitney test

a: Statistically significant with Tramadol $p=0.018$

b: Statistically significant with Tramadol $p=0.020$

c: Statistically insignificant with Clonazepam $p=0.405$

$*$ : Statistically significant at $\mathbf{p} \leq \mathbf{0 . 0 5}$

Table (5): Relation between concentration of the drugs and duration of abuse

\begin{tabular}{|c|c|c|c|c|c|}
\hline \multirow{2}{*}{$\begin{array}{c}\text { Concentration } \\
\text { calculated }(\mathrm{ng} / \mathrm{ml})\end{array}$} & \multicolumn{3}{|c|}{ Duration of abuse } & \multirow[t]{2}{*}{$\mathbf{H}$} & \multirow[t]{2}{*}{$\mathbf{P}$} \\
\hline & $>2$ year & 1 - 2 year & $<1$ year & & \\
\hline Tramadol & $(n=2)$ & $(n=4)$ & $(n=4)$ & & \\
\hline Min.-Max. & $22.7-31.7$ & $7.9-8.4$ & $1.3-1.6$ & \multirow[t]{3}{*}{$7.855^{*}$} & \multirow[t]{3}{*}{$0.020^{*}$} \\
\hline Mean \pm SD. & $27.2 \pm 6.4$ & $8.2 \pm 0.2$ & $1.5 \pm 0.2$ & & \\
\hline Median & 27.2 & 8.2 & 1.53 & & \\
\hline Sig. bet. Periods & \multicolumn{3}{|c|}{$\mathrm{p}_{1}=0.064, \mathrm{p}_{2}=0.064, \mathrm{p}_{3}=0.021^{*}$} & & \\
\hline Clonazepam & $(\mathbf{n}=3)$ & $(\mathbf{n}=3)$ & $(n=4)$ & & \\
\hline Min.-Max. & $3.87-3.89$ & $3.87-3.87$ & $3.86-3.87$ & \multirow[t]{3}{*}{$8.018^{*}$} & \multirow[t]{3}{*}{$0.018^{*}$} \\
\hline Mean \pm SD. & $3.88 \pm 0.02$ & $3.87 \pm 0.01$ & $3.86 \pm 0.01$ & & \\
\hline Median & 3.88 & 3.88 & 3.87 & & \\
\hline Sig. bet. Periods & \multicolumn{3}{|c|}{$\mathrm{p}_{1}=0.050^{*}, \mathrm{p}_{2}=0.034^{*}, \mathrm{p}_{3}=0.034^{*}$} & & \\
\hline Phenobarbital & $(\mathbf{n}=3)$ & $(n=4)$ & $(\mathbf{n}=3)$ & & \\
\hline Min.-Max. & $4.0-4.4$ & $3.2-3.7$ & $2.6-2.9$ & \multirow[t]{3}{*}{$8.018^{*}$} & \multirow[t]{3}{*}{$0.018^{*}$} \\
\hline Mean \pm SD. & $4.2 \pm 0.2$ & $3.4 \pm 0.2$ & $2.8 \pm 0.1$ & & \\
\hline Median & 4.1 & 3.3 & 2.8 & & \\
\hline Sig. bet. Periods & \multicolumn{3}{|c|}{$\mathrm{p}_{1}=0.034^{*}, \mathrm{p}_{2}=0.050^{*}, \mathrm{p}_{3}=0.034^{*}$} & & \\
\hline
\end{tabular}

H,p: $H$ and p values for Kruskal Wallis test, Significance between groups was done using

Mann Whitney test

p1: $p$ value for comparing between $>2$ year and $1-2$ year

p2: $p$ value for comparing between $>2$ year and $<1$ year

p3: $p$ value for comparing between 1 - 2 year and $<1$ year

$*$ : Statistically significant at $\mathbf{p} \leq \mathbf{0 . 0 5}$ 
Table (6): Relation between age and the concentration of drugs calculated in the drug abuser group

\begin{tabular}{|c|c|c|c|c|c|}
\hline \multirow{2}{*}{$\begin{array}{c}\text { Concentration } \\
\text { calculated (ng/ml) }\end{array}$} & \multicolumn{3}{|c|}{ Age } & \multirow[t]{2}{*}{$\mathbf{H}$} & \multirow[t]{2}{*}{$\mathbf{P}$} \\
\hline & $\begin{array}{l}18-<25 \\
(n=12)\end{array}$ & $\begin{array}{c}25-<30 \\
(n=9)\end{array}$ & $\begin{array}{l}30-35 \\
(n=9)\end{array}$ & & \\
\hline \multicolumn{6}{|l|}{ Tramadol } \\
\hline Min.-Max. & $8.15-31.68$ & $1.62-8.14$ & $1.26-1.61$ & \multirow[t]{3}{*}{$8.018^{*}$} & \multirow[t]{3}{*}{$0.018^{*}$} \\
\hline Mean \pm SD. & $17.73 \pm 11.51$ & $5.88 \pm 3.69$ & $1.44 \pm 0.17$ & & \\
\hline Median & 15.55 & 7.88 & 1.46 & & \\
\hline \multicolumn{6}{|l|}{ Clonazepam } \\
\hline Min.-Max. & $3.87-3.88$ & $3.87-3.87$ & $3.86-3.87$ & \multirow[t]{3}{*}{$7.000^{*}$} & \multirow[t]{3}{*}{$0.030^{*}$} \\
\hline Mean \pm SD. & $3.88 \pm 0.03$ & $3.87 \pm 0.02$ & $3.87 \pm 0.02$ & & \\
\hline Median & 3.88 & 3.87 & 3.87 & & \\
\hline \multicolumn{6}{|l|}{ Phenobarbital } \\
\hline Min.-Max. & $3.66-4.39$ & $2.87-3.41$ & $2.62-3.22$ & \multirow[t]{3}{*}{$7.000^{*}$} & \multirow[t]{3}{*}{$0.030^{*}$} \\
\hline Mean \pm SD. & $4.04 \pm 0.30$ & $3.16 \pm 0.27$ & $2.87 \pm 0.31$ & & \\
\hline Median & 4.06 & 3.20 & 2.78 & & \\
\hline
\end{tabular}

H,p: $H$ and p values for Kruskal Wallis test

$*$ : Statistically significant at $\mathbf{p} \leq \mathbf{0 . 0 5}$

Table (7): Relation between residence and the concentration of drugs calculated in drug abuser group

\begin{tabular}{|c|c|c|c|c|}
\hline \multirow{2}{*}{$\begin{array}{c}\text { Concentration } \\
\text { calculated }(\mathrm{ng} / \mathrm{ml})\end{array}$} & \multicolumn{2}{|c|}{ Residence } & \multirow[t]{2}{*}{$\mathbf{U}$} & \multirow[t]{2}{*}{$\mathbf{P}$} \\
\hline & $\begin{array}{l}\text { Urban } \\
(n=18)\end{array}$ & $\begin{array}{c}\text { Rural } \\
(n=12)\end{array}$ & & \\
\hline \multicolumn{5}{|l|}{ Tramadol } \\
\hline Min.-Max. & $8.15-31.68$ & $1.26-8.14$ & \multirow[t]{3}{*}{$0.000^{*}$} & \multirow[t]{3}{*}{$0.011^{*}$} \\
\hline Mean \pm SD. & $17.73 \pm 11.51$ & $3.66 \pm 3.37$ & & \\
\hline Median & 15.55 & 1.61 & & \\
\hline \multicolumn{5}{|l|}{ Clonazepam } \\
\hline Min.-Max. & $3.87-3.88$ & $3.86-3.87$ & \multirow[t]{3}{*}{$1.000^{*}$} & \multirow[t]{3}{*}{$0.019^{*}$} \\
\hline Mean \pm SD. & $3.88 \pm 0.04$ & $3.87 \pm 0.02$ & & \\
\hline Median & 3.88 & 3.87 & & \\
\hline \multicolumn{5}{|l|}{ Phenobarbital } \\
\hline Min. - Max. & $3.81-4.39$ & $2.62-3.66$ & \multirow[t]{3}{*}{$1.000^{*}$} & \multirow[t]{3}{*}{$0.019^{*}$} \\
\hline Mean士SD. & $3.98 \pm 0.41$ & $3.06 \pm 0.38$ & & \\
\hline Median & 4.06 & 3.03 & & \\
\hline
\end{tabular}

U, p: p values for Mann Whitney test

$*$ : Statistically significant at $\mathbf{p} \leq \mathbf{0 . 0 5}$ 
Table (8): Relation between the education and the concentration of drugs calculated in drug abusers

\begin{tabular}{|c|c|c|c|c|c|}
\hline \multirow{2}{*}{$\begin{array}{c}\text { Concentration } \\
\text { calculated } \\
(\mathbf{n g} / \mathbf{m l})\end{array}$} & \multicolumn{3}{|c|}{ Education } & \multirow[t]{2}{*}{$\mathbf{H}$} & \multirow[t]{2}{*}{$\mathbf{P}$} \\
\hline & $\begin{array}{l}\text { Illiterate } \\
(n=12)\end{array}$ & $\begin{array}{c}\text { Secondary } \\
\text { school } \\
(n=6)\end{array}$ & $\begin{array}{c}\text { University } \\
(n=12)\end{array}$ & & \\
\hline \multicolumn{6}{|l|}{ Tramadol } \\
\hline Min.-Max. & $1.61-8.14$ & $1.26-1.46$ & $8.15-31.68$ & \multirow[t]{3}{*}{$7.855^{*}$} & \multirow[t]{3}{*}{$0.020^{*}$} \\
\hline Mean \pm SD. & $4.81 \pm 3.70$ & $1.36 \pm 0.14$ & $17.73 \pm 11.51$ & & \\
\hline Median & 4.75 & 1.36 & 15.55 & & \\
\hline \multicolumn{6}{|l|}{ Clonazepam } \\
\hline Min.-Max. & $3.86-3.87$ & $3.87-3.87$ & $3.87-3.88$ & \multirow[t]{3}{*}{5.945} & \multirow[t]{3}{*}{$0.051^{*}$} \\
\hline Mean \pm SD. & $3.87 \pm 0.03$ & $3.86 \pm 0.02$ & $3.88 \pm 0.04$ & & \\
\hline Median & 3.87 & 3.86 & 3.88 & & \\
\hline \multicolumn{6}{|l|}{ Phenobarbital } \\
\hline Min.-Max. & $2.87-3.41$ & $2.62-2.78$ & $3.66-4.39$ & \multirow[t]{3}{*}{$7.855^{*}$} & \multirow[t]{3}{*}{$0.020^{*}$} \\
\hline Mean \pm SD. & $3.17 \pm 0.23$ & $2.70 \pm 0.12$ & $4.04 \pm 0.30$ & & \\
\hline Median & 3.21 & 2.70 & 4.06 & & \\
\hline
\end{tabular}

$H, p: H$ and $p$ values for Kruskal Wallis test

$*$ : Statistically significant at $\mathbf{p} \leq \mathbf{0 . 0 5}$

Table (9): Relation between the occupation and the concentration of drugs in the drug abuser group

\begin{tabular}{|c|c|c|c|c|c|c|}
\hline \multirow{2}{*}{$\begin{array}{c}\text { Concentration } \\
\text { calculated } \\
(\mathbf{n g} / \mathbf{m l}) \\
\end{array}$} & \multicolumn{4}{|c|}{ Occupation } & \multirow[t]{2}{*}{$\mathbf{H}$} & \multirow[t]{2}{*}{$\mathbf{P}$} \\
\hline & $\begin{array}{c}\text { Worker } \\
(n=12)\end{array}$ & $\begin{array}{c}\text { Student } \\
(n=6)\end{array}$ & $\begin{array}{c}\text { Employee } \\
(n=6)\end{array}$ & $\begin{array}{c}\text { Unemployed } \\
(n=6)\end{array}$ & & \\
\hline \multicolumn{7}{|l|}{ Tramadol } \\
\hline Min.-Max. & $8.15-31.68$ & $7.88-8.14$ & $1.61-1.62$ & $1.26-1.46$ & \multirow[t]{3}{*}{$8.291^{*}$} & \multirow[t]{3}{*}{$0.040^{*}$} \\
\hline Mean \pm SD. & $\begin{array}{c}17.73 \pm 11.5 \\
1\end{array}$ & $\begin{array}{c}8.01 \pm 0.1 \\
8\end{array}$ & $1.61 \pm 0.01$ & $1.36 \pm 0.14$ & & \\
\hline Median & 15.55 & 8.01 & 1.61 & 1.36 & & \\
\hline \multicolumn{7}{|l|}{ Clonazepam } \\
\hline Min.-Max. & $3.87-3.88$ & $3.87-3.87$ & $3.87-3.87$ & $3.86-3.87$ & \multirow[t]{3}{*}{$7.855^{*}$} & \multirow[t]{3}{*}{$0.049^{*}$} \\
\hline Mean \pm SD. & $3.89 \pm 0.02$ & $\begin{array}{c}3.88 \pm 0.0 \\
2\end{array}$ & $3.87 \pm 0.02$ & $3.86 \pm 0.02$ & & \\
\hline Median & 3.89 & 3.88 & 3.87 & 3.86 & & \\
\hline \multicolumn{7}{|l|}{ Phenobarbital } \\
\hline Min.-Max. & $3.66-4.39$ & $3.22-3.41$ & $2.78-3.87$ & $2.62-3.20$ & \multirow[t]{3}{*}{$7.855^{*}$} & \multirow[t]{3}{*}{$0.049^{*}$} \\
\hline Mean \pm SD. & $4.04 \pm 0.30$ & $\begin{array}{c}3.31 \pm 0.1 \\
4\end{array}$ & $2.91 \pm 0.06$ & $2.82 \pm 0.41$ & & \\
\hline Median & 4.06 & 3.31 & 2.91 & 2.82 & & \\
\hline
\end{tabular}

H,p: $H$ and p values for Kruskal Wallis test

$*$ : Statistically significant at $\mathbf{p} \leq \mathbf{0 . 0 5}$ 
Table (10): Relation between the family history of abuse and the concentration calculated in the drug abuser group

\begin{tabular}{|c|c|c|c|c|}
\hline \multirow{2}{*}{$\begin{array}{c}\text { Concentration } \\
\text { calculated (ng/ml) }\end{array}$} & \multicolumn{2}{|c|}{ Family history } & \multirow[t]{2}{*}{$\mathbf{U}$} & \multirow[t]{2}{*}{$\mathbf{P}$} \\
\hline & Negative $(n=4)$ & Positive (n=6) & & \\
\hline \multicolumn{5}{|l|}{ Tramadol } \\
\hline Min.-Max. & $1.26-1.62$ & $7.88-31.68$ & \multirow[t]{3}{*}{$0.000^{*}$} & \multirow[t]{3}{*}{$0.011^{*}$} \\
\hline Mean \pm SD & $1.49 \pm 0.17$ & $14.49 \pm 10.23$ & & \\
\hline Median & 1.53 & 8.29 & & \\
\hline \multicolumn{5}{|l|}{ Clonazepam } \\
\hline Min.-Max. & $3.86-3.87$ & $3.87-3.88$ & \multirow[t]{3}{*}{$1.000^{*}$} & \multirow[t]{3}{*}{$0.019^{*}$} \\
\hline Mean \pm SD. & $3.87 \pm 0.02$ & $3.88 \pm 0.04$ & & \\
\hline Median & 3.87 & 3.88 & & \\
\hline \multicolumn{5}{|l|}{ Phenobarbital } \\
\hline Min.-Max. & $2.62-3.41$ & $3.20-4.39$ & \multirow[t]{3}{*}{$2.000^{*}$} & \multirow[t]{3}{*}{$0.033^{*}$} \\
\hline Mean \pm SD. & $2.92 \pm 0.34$ & $3.77 \pm 0.49$ & & \\
\hline Median & 2.82 & 3.83 & & \\
\hline
\end{tabular}

\section{DISCUSSION}

Drug dependence is defined as enthusiastic substance use inspite of serious negative results. It is a cluster of cognitive, behavioral, and physiological symptoms. Impulsive utility is the cardinal component of addiction. It implies that the influenced individual cannot control substance use for a significant period of time, in spite of effective motivations to do so. Some drug related health problems, drug associated arrest, or danger of losing one's activity or life partner can occur (Weiss, 2012).

Fingerprint is an impression left by the friction ridges of a human finger. The recovery of fingerprints from a crime scene is a vital technique for forensic science. Fingerprints are easily deposited on suitable surfaces (such as glass or metal or polished stone) by the natural secretions of sweat from the eccrine glands that are present in epidermal ridges (Susilo et al., 2000).

Medico-legally, the recognition of drugs of abuse from fingerprints is useful in case of crimes under the effect of drugs, rape, driving under the effect of drugs, psychiatric disorders and determination of the reason of death (Jones, 2016).

The capacity to specifically recognize a specific molecular ion, which can uniquely distinguish an illegal drug from a fingerprint, is greatly helpful for forensic work. Thus, various research groups are creating strategies in view of either MS alone or chromatography combined with MS detection (Hazarika et al., 2009).

In the past, most analytical chemistry specialists considered LCMS to be difficult to operate, insensitive, expensive, and a research tool for a few specialists only (Karst, 2004)

The apparatus has been enhanced and the analysts have learned to more or less overcome the disadvantages and difficulties with LC-MS analysis (Maurer, 2006).

For example, relevant matrix impacts can often be avoided by 
appropriate specimen clean-up, chromatographic changes, reagent alterations and effective internal standardization (Peters, 2006).

The testing of drug abuse is authentic in order to assure the abuse and the testing method is usually done by laboratory investigation of urine, blood and hair (Chen et al., 2012).

However, many problems of sample taking difficulties and risk of adulteration or alternation appear. The utilization of other biological specimens such as saliva, skin sweat, fingerprint deposits, exhaled breath and fingernails in drug testing produces some advantages and initiates more attention (Lin et al., 2004).

The aim of the present work was to assess the possibility of detection of some drugs of abuse from fingerprints using LC-MS.

The current study was conducted on 60 male individuals. The diagnosis of drug dependence was based on the current Diagnostic and Statistical Manual of Mental Disorders (DSM-V) and screening tests on urine for tramadol, clonazepam and phenobarbital. A control group was included in the study. The control group was of comparable age.

Screening immunoassay test for the drugs of abuse was made first using urine sample from all participants then fingerprints from the abusers and control individuals, taken on a filter paper. Identification of the fingerprints was made first using optical methods (UV Lamp) then LC-MS analysis of the fingerprints was performed.

In the present research, all samples of fingerprints from the drug abusers showed positive results with LC-MS, while all samples from the control individuals showed negative results which confirm that the test has $100 \%$ specificity and sensitivity.

This coincides with the study done by Zhang et al (2014) who showed that all fingerprints samples of amphetamine and methamphetamine abusers showed positive results with LC-MS, while all samples from the control individuals showed negative results.

The high specificity and sensitivity result from the ability of LC-MS to detect drugs at the sub-femtogram level particularly in alternative matrices that has great applicability in quantification in clinical and forensic toxicology (Momoh et al., 2010).

This is medico legally important as LC-MS plays a major role in detection of drugs of abuse, drug-facilitated sexual assault and detection of drugs of forensic importance in postmortem cases (McGrath and Jenkins, 2009).

In 2004, Day et al studied drugs of abuse in fingerprints using Raman spectroscopy. They also concluded that all of the drugs of abuse were successfully detected in fingerprints using this method.

In contrast, the study conducted by Krumbiegel et al (2014) on the drugs of abuse from the nails of abusers using LC-MS revealed that about $10 \%$ of the cases showed negative results.

Regarding the relation between the concentration of the drugs and the duration of abuse, the current study revealed that abusers of tramadol, clonazepam and phenobarbital showed the highest mean concentrations of the drugs if the duration of abuse was more than two years while it showed the lowest mean concentration of the drugs if the duration of drug intake was less than one year, which was significantly different. This means that the 
concentration of the drugs increases as the duration of drug intake increases.

This can be explained by the fact that the level of the drugs in the fingerprints is directly related to those detected in the plasma, so any increase in the duration of abuse will increase the level of the drugs in the plasma and subsequently in the fingerprints.

The current findings are in agreement with the data reported by Karch (2015), who also detected that the concentration of the drugs directly correlate with the duration of abuse.

Concerning the relation between the concentration of the drugs and age, the present study revealed that the concentration of tramadol, clonazepam and phenobarbital among drug abusers was higher in the age group $18-<25$ years than the age group $25-<30$ and $30-$ 35 years. The age group 30-35 years showed the lowest mean concentration. There was a significant difference between all of them.

These findings agree with the study done by Bradshaw et al (2013) which stated that substance abuse by young people had increased in the past decade and illicit drug use is a youth phenomenon. The rate of consumption is higher among 18-24 year old males. Also, the risk of illicit drug initiation increased steadily from ages 12-21 years.

This could be explained by the fact that young people usually want to live happiness and self-confidence. Moreover, this is the period of active life, work and responsibilities with more liability for facing problems, emotional difficulties, exposure to stress and fear of failure. There is a false belief that drug use can help them establish their individuality, independence, their ways of living and to show their rejection of social standards.

Additionally, experimentation with sense of new experiences is normal and necessary aspect of youth development. The initiation of illicit substance abuse often starts as a form of experimentation for recreational purposes, for thrill seeking or as a way to bond with peers. Experimentation may be followed by more frequent drug use that may progress to more serious abuse problems.

In agreement with the current study Rather et al (2013) made a study over a period of one year (June 2008 to May 2009), on 198 Indian male persons with substance abuse who were admitted to the drug abuse treatment centers. All were males with a mean age of 26.8 years.

The majority of drug dependent individuals in the current study (60\%) were from urban areas. This demographic pattern may reflect availability and accessibility to drugs.

Comparison between urban and rural areas regarding the mean concentration of drugs of abuse among drug abusers revealed a significant difference where the mean concentration of tramadol, clonazepam and phenobarbital in urban areas was significantly higher than in the rural areas.

Most of our cases were taken from Alexandria that is an urban locality in Egypt, which might be an impression of the expansion in urbanization, accessibility to treatment or a true prevalence of substance abuse in the urban population. The different components which can prompt an expanding number of drug addicts among the urban population may be the absence of parental love and care in 
modern families where both parents are working, breaking down of the old family framework and a decay of good esteems in the youthful age (Harpham 1994).

Regarding the occupation, the mean concentration of tramadol, clonazepam and phenobarbital was higher among workers than among students, whose mean concentration was higher than employees while the unemployed group had the least mean concentration of the tested drugs of abuse.

This is in accordance with results obtained by El-Sawy et al (2010) who found that the highest percentage of drugs of abuse was among manual workers. They concluded that the prevalence of drug addiction varied with different occupations.

Concerning the educational level, the mean concentration of the studied drugs was higher among the highly educated group than the non-educated one. But the secondary school educated abusers showed the least mean concentration for these drugs.

This agrees with the results reported by El-Sawy et al (2010).

In contrast to the present study, Rather et al (2013) reported that the highest percentage of drug dependent individuals in his study $(53.5 \%)$ was among the high school individuals, while the lowest percentages were among both; the non-educated $(8.1 \%)$ and the highly educated individuals (13.1\%).

This difference may be due to the probability of impaired cognitive function, lower scholastic performance, and school dropout, especially if the substance abuse starts in preadolescence.

The majority of drug dependent individuals in the current study $(63.3 \%)$ had positive family history for substance abuse. The family members involved were parents, uncles, cousins or siblings.

In case of abusers with positive family history, it was found that the mean concentration of tramadol, clonazepam and phenobarbital was significantly higher than in abusers with negative family history.

In 2015, Rita found that the persons with positive family history of drugs of abuse showed risk for developing addiction to drugs and risk for increased drug intake greater than persons with negative family history.

\section{CONCLUSION \& RECOMMENDATION}

From the current work, it could be concluded that drugs of abuse can be detected from fingerprints using LC-MS with high specificity and sensitivity especially in criminal cases when other methods are inconclusive.

So it is recommended to verify the applicability of this method in criminal cases involving drug handlers or on documents touched by abusers when only trace evidences are to be detected.

\section{LIMITATION OF THE STUDY}

Although it is a confirmatory test, it has some disadvantages as it is expensive, needs training to operate and not widely available in Egypt.

But it is of tremendous value in cases of drug abusers when fingerprints are left behind on different handled documents and surfaces.

\section{ACKNOWLEDGEMENT}

We would like to express our deepest gratitude and appreciation to all participants in the study. 
ETHICAL APPROVAL

This study followed the ethical guidelines of ethical committee of Alexandria University and a written informed consent was taken from all participants.

\section{CONFLICT OF INTEREST}

There is no conflict of interest related to the publication of this paper.

\section{FUNDING}

None

\section{REFERENCES}

American Psychiatric Association. (2013): Diagnostic and Statistical Manual of Mental Disorders, Text Revision. $4^{\text {th }}$ ed. Washington, DC: American Psychiatric Association.

Barnes, A.J.; Smith, M.L.; Kacinko, S.L.; Schwilke, E.W.; Cone, E.J.; Moolchan, E.T. and Huestis, M.A. (2008): Excretion of methamphetamine and amphetamine in human sweat following controlled oral methamphetamine administration. Clinical chemistry, 54(1): 172-180.

Bradshaw, R.; Wolstenholme, R.; Ferguson, L.S.; Sammon, C.; Mader, K.; Claude, E.; and Francese, S. (2013): Spectroscopic imaging based approach for condom identification in condom contaminated fingermarks. Analyst, 138(9): 2546-2557.

Chaimbault, P. (2014): The Modern art of identification of natural substances in whole plants. In: Jacob, C.; Kirsch, G.; Slusarenko, A.; Winyard, P.G. and Burkholz, T. (eds). Recent Advances in Redox Active Plant and Microbial Products: From Basic Chemistry to Widespread Applications in
Medicine and Agriculture. London: Springer Netherlands; P.31-97.

Chen, Y.; Zhu, J.; Yu, Z.; Zhang, Y.; and Liu, Y. (2012): Determination of three drugs and their metabolites in saliva by ultra performance liquid chromatography-tandem mass spectrometry. Se pu $=$ Chinese Journal of chromatography, 30(11): 1148-1152.

Clemons, K.; Wiley, R.; Waverka, K.; Fox, J.; Dziekonski, E. and Verbeck, G.F. (2013): Direct Analyte-Probed Nanoextraction Coupled to Nanospray IonizationMass Spectrometry of Drug Residues from Latent Fingerprints. Journal of forensic sciences, 58(4): 875-880.

Copeman, M. (2003): Drug supply and drug abuse. Canadian Medical Association Journal, 168(9): 1113.

Czekanski, P.; Fasola, M. and Allison, J. (2006): A mechanistic model for the superglue fuming of latent fingerprints. Journal of forensic sciences, 51(6): 1323-1328.

Day, J.S.; Edwards, H.G.; Dobrowski, S.A. and Voice, A.M. (2004): The detection of drugs of abuse in fingerprints using Raman spectroscopy II: cyanoacrylatefumed fingerprints. Spectrochimica Acta Part A: Molecular and Biomolecular Spectroscopy, 60(8): 1725-1730.

El-Sawy, H.; Abdel Hay, M. and Badawy, A. (2010): Gender differences in risks and pattern of drug abuse in Egypt. Egypt $\mathbf{J}$ Psychiat Neurosurg, 47: 413-418.

Harpham, T. (1994): Urbanization and mental health in developing countries: A research role for social scientists, public health 
professionals and social psychiatrists. Social science \& medicine, 39(2):233-245

Hazarika, P.; Jickells, S.M. and Russell, D.A. (2009): Rapid detection of drug metabolites in latent fingermarks. Analyst, 134: 93-96.

Hazarika, P.; Jickells, S.M.; Wolff, K. and Russell, D.A. (2010): Multiplexed detection of metabolites of narcotic drugs from a single latent fingermark. Analytical chemistry 82(22): 9150-9154.

Ifa, D.R.; Manicke, N.E.; Dill, A.L. and Cooks, R.G. (2008): Latent fingerprint chemical imaging by mass spectrometry. Science, 321(5890):805.

Jones, J.D.; Comer, S.D.; (2015): A review of pharmacogenetic studies of substance related disorders. Drug alcohol dependence, 152: 1-14.

Jones, A.W. (2016): Introduction to forensic toxicology and the value of a nationwide database. In: Davies $S$. Johnston A, Holt D. (eds). Forensic Toxicology: Drug Use and Misuse. 1st ed. British: Royal Society of Chemistry; P.1-29

Karch, S.B. and Drummer, O. (2015): Karch's Pathology of Drug Abuse. $5^{\text {th }}$ ed. United States: CRC Press.

Karst, U. (2004): Liquid chromatography-mass spectrometry: reaching maturity rapidly. Analytical and bioanalytical chemistry, 378(4): 841-841.

Krumbiegel, F.; Hastedt, M. and Tsokos, M. (2014): Nails are a potential alternative matrix to hair for drug analysis in general unknown screenings by liquidchromatography quadrupole timeof-flight mass spectrometry.
Forensic science, medicine, and pathology, 10(4): 496-503.

Kuwayama, K.; Yamamuro, T.; Tsujikawa, K.; Miyaguchi, H.; Kanamori, T.; Iwata, Y.T. and Inoue, H. (2014): Time-course measurements of drugs and metabolites transferred from fingertips after drug administration: usefulness of fingerprints for drug testing. Forensic Toxicology, 32(2): 235-242.

Leggett, R.; Lee-Smith, E.E.; Jickells, S.M. and Russell, D.A. (2007): "Intelligent" fingerprinting: simultaneous identification of drug metabolites and individuals by using antibody-functionalized

nanoparticles. Angewandte Chemie, 119(22): 4178-4181.

Lin, D.L.; Yin, R.M.; Liu, H.C.; Wang, C.Y. and Liu, R.H. (2004): Deposition characteristics of methamphetamine and amphetamine in fingernail clippings and hair sections. Journal of analytical toxicology, 28(6): 411417.

Maurer, H.H. (2006): Hyphenated mass spectrometric techniquesindispensable tools in clinical and forensic toxicology and in doping control. J Mass Spectrom, 41(11):1399-413.

Maurer, H.H. (1992): Systematic toxicological analysis of drugs and their metabolites by gas chromatography-mass spectrometry. Journal of Chromatography B: Biomedical Sciences and Applications, 580(1-2): 3-41.

McGrath, K.K. and Jenkins, A.J. (2009): Detection of drugs of forensic importance in postmortem bone. The American journal of 
forensic medicine and pathology, 30(1): 40-44.

Momoh, P.; Fandino, A.; Aisawa, E.; Schlabach, T.; Miller, K. and Stafford, G. (2010): Technical overview: iFunnel technology for enhanced sensitivity in tandem LC/MS. Agilent Technol Available from: https://www. agilent.com/cs/library/technicalover views/Public/59905891en_1o\%20C MS.pdf [Accessed on: 3 June, 2017]

Ng, P.H.; Walker, S.; Tahtouh, M. and Reedy, B. (2009): Detection of illicit substances in fingerprints by infrared spectral imaging. Analytical and bioanalytical chemistry, 394(8): 2039-2048.

Peters, F.T. (2006): Method Validation using LC-MS. In: Polettini A (ed). Applications of liquid chromatography-mass spectrometry in toxicology. London: Pharmaceutical Press; P.71-95

Raes, E. and Verstraete, A.G. (2005); Usefulness of roadside urine drug screening in drivers suspected of driving under the influence of drugs (DUID). Journal of analytical toxicology, 29(7):632-636.

Rather, Y.H.; Bashir, W.; Sheikh, A.A.; Amin, M. and Zahgeer, Y.A. (2013): Socio-demographic and Clinical Profile of Substance Abusers Attending a Regional Drug De-addiction Centre in Chronic Conflict Area: Kashmir, India. The Malaysian journal of medical sciences, 20(3): 31-38.

Rita, M. (2015): Living with Addiction. Available from: http://www.recovery.org/pro/articles /family-history-and-addiction-riskwhat-you-need-to-know-to-beat-theodds[Accessed on: 3 June, 2017]
Saferstein, R. (2006): Criminalistics: An introduction to forensic science. $9^{\text {th }}$ ed. New Jersey: Prentice Hall.

Susilo, W.; Safavi-Naini, R.; Gysin, M. and Seberry, J. (2000): A new and efficient fail-stop signature scheme. The Computer Journal, 43(5): 430-437.

Tracqui, A.; Kintz, P.; Ludes, B. and Mangin, P. (1997): Highperformance liquid chromatography-ion spray mass spectrometry for the specific determination of digoxin. Journal of chromatography. B, Biomedical sciences and applications, 692(1): 101-109.

Weiss, R.D. (2012): Drug abuse and dependence. In: Goldman L, Ausiello D (eds). Cecil Medicine. $24^{\text {th }}$ ed. Philadelphia: Saunders Elsevier; P.146-158.

Wood, E.; Tyndall, M.W.; Spittal, P.M.; Li, K.; Anis, A.H. and Hogg, R.S. (2003): Impact of supply-side policies for control of illicit drugs in the face of the AIDS and overdose epidemics: investigation of a massive heroin seizure. Canadian Medical Association journal, 168(2):165169.

Zhang, T.; Chen, X.; Yang, R. and Xu, Y. (2015): Detection of methamphetamine and its main metabolite in fingermarks by liquid chromatography-mass spectrometry. Forensic science international, 248:10-4. 


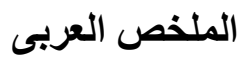

الكثف عن بعض العقاقير من الإصابات من الأصابع باستخدام القياس الطيفي الكمي

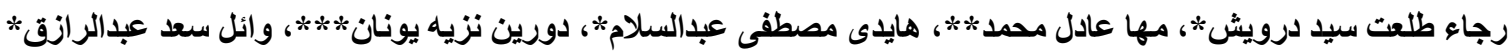

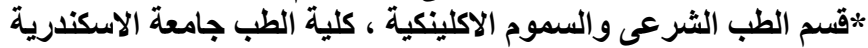

** قسم التكنولوجيا الحيوية الطبية ، معهد بحوث الهندسة الوراثية والتكنولوجيا الحيوية ، مدينة البحث العلمي وتطبيقات التكنولوجية

*** * * * الباثولوجية الكيميائية والاكلينكية، كلية الطب، جامعة الاسكندرية

الأساس المنطقي والخلفية: يعتبر تعاطي المخدرات مساهما رئيسيا في كل من المراضة واضئ والوفيات الطبية في جميع أنحاء

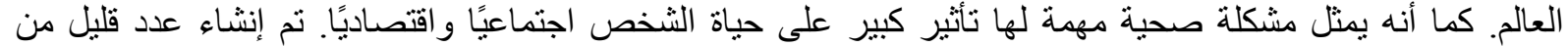

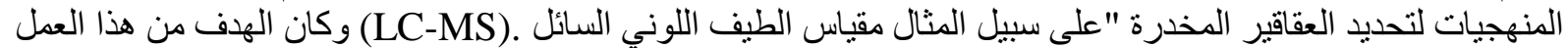

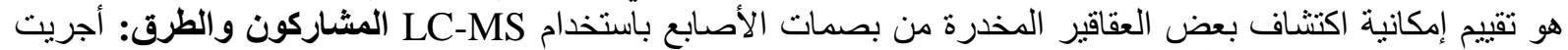

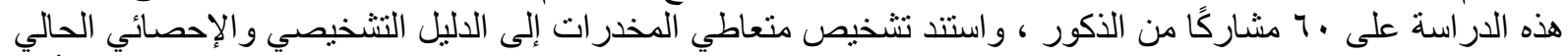

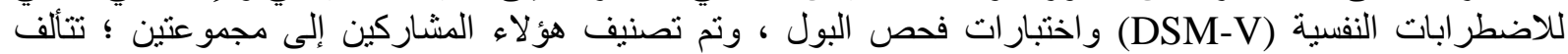

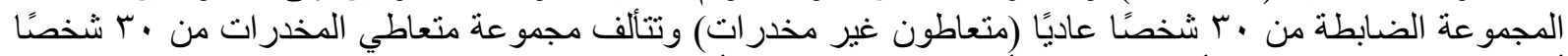

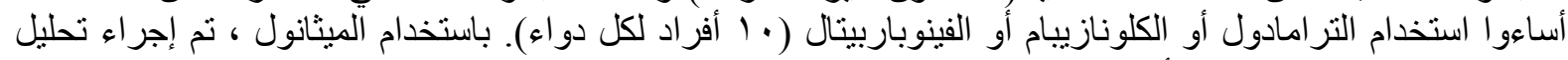
LC-MS.

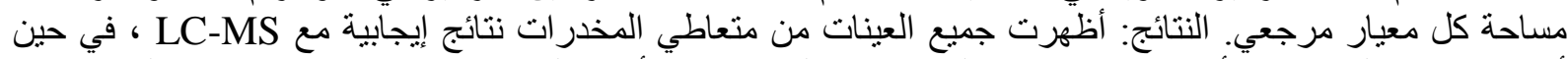

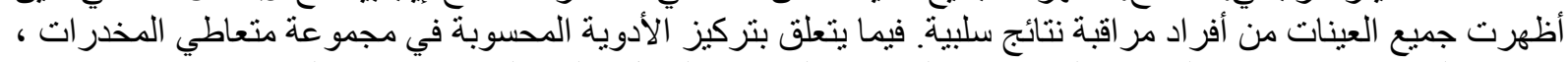

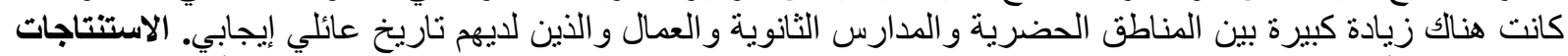

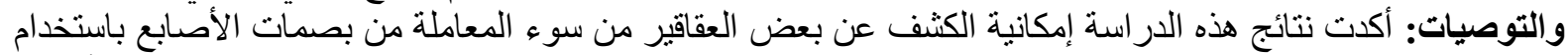
LC-MS.

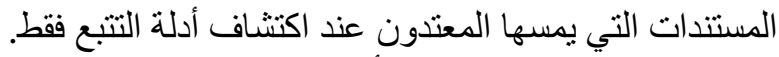

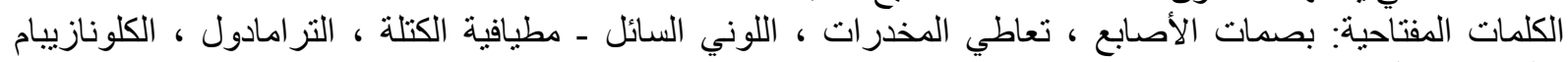
و الفينوباربيتال. 